\title{
Performance Assessment for a Sustainable Supply Chain at Local Level
}

\author{
Prevez L; Giannetti B.F; Almeida CMVB and Agostinho F \\ Paulista University. São Paulo, Brazil \\ \{lprevez50, feniagostinho\}@gmail.com
}

\begin{abstract}
This article aims to provide a tool to diagnose the supply chain management from a performance reference model allowing evaluating the links individually and the supply chain as a whole, taking as case study the mango pulp supply chain at local level in Santiago de Cuba in Cuba. The reference model considers a territorial approach to rural development that do not have a specialized logistics system. The identification and better understanding of the obstacles that limit the supply chain is the great importance both for the definition of public policies and for awareness and making sustainable decisions of companies operating in the sector.
\end{abstract}

Keywords: Supply chain at local level $\cdot$ Sustainable $\cdot$ Performance reference model · Agroindustry · Mango

\section{Introduction}

The Agriculture is ceasing to be an area isolated by force of industrialization and close relationships between several production units when concentrated in a specific territory. It increase and retain value added farmer production in rural areas $[1,2,3]$ due to the use of local culture, valuing women's work and recognition of local knowledge through selection, washing, sorting, storage, preservation, processing, packaging, transport and marketing fruits [4]. Correa and Gomez [5] raised that the supply chain has become a key concept because consider business processes, people, organization, technology and physical infrastructure for enterprises.

The Management Supply Chain is a systemic approach that aims integrating the various direct and indirect actor in a chain, in order to gain competitive advantages, through cooperation with other companies that are part of the same competitive environment [6]. However, it could be defined "as a methodology developed to align all production activities in a synchronized manner in order to reduce costs, minimize cycles and maximize the value perceived by the end customer through the breaking of barriers between departments and areas" [7]. With the expansion of the concept of management, demand was raised for the development of models as a reference guide to assess performance, integrating concepts into a unified instrument, forming a systemic structure of management $[8,9]$. Acevedo et al. [10] add that the reference models can

adfa, p. 1, 2011.

(C) Springer-Verlag Berlin Heidelberg 2011 
identify strengths and weaknesses, barriers and opportunities offered by the environment in order to develop and implement a strategic plan for development. However, the other barriers to define a reference model are the internal strategy of each company that is not necessarily linked to the interests of the whole chain, the influence of the stronger actors' strategy upon the rests and the involvement of various members in various chains, difficulty implementation a single strategy [11].

Some authors attribute the lack of academic publications on real cases due to the diversity of companies, indirect stakeholders in the chain and the complexity observed in logistics processes given by interactions numbers, strategic alliances and contracts $[2,11,12]$. Already, Seuring [13] and [3] attribute this to the complexity that arises when different actors establish a business with shared objectives, conflict between participants, lack of appropriate measures that reduce customer expectations and chain optimization.

This article aims to provide a tool to diagnose the supply chain management from a performance reference model for evaluating the links individually and the supply chain as a whole, taking as case study the mango pulp supply chain at local level in Santiago de Cuba in Cuba.

\section{$2 \quad$ Method}

\subsection{Supply Chain Case Study}

The supply chain at local level, under study, was selected in the Santiago de Cuba province during 2012 mango season. The area designated for pulp mango production in monoculture regimen is the 130 ha with about 13 years old, an annual production of 1300 t. Nine associated producers compose the primary producers with 71 workers where $70 \%$ live on the property. The pulp industry processes daily $2 t$ of mango pulp hot filled into 3 liter cans. The 38 workers support this activity. The main input suppliers are the same that provide the provincial level, so this study does not take into account the focal company. The chain receives support from government organizations such as research institutes, Ministry of Agriculture, Logistics Group, among others. The logistics system consists in transportation of the fresh fruit to the pulp industry and the pulp distribution in the local markets (4 points of sales, and 10 mobile sellers), by two independent companies. According with [3], this is a common situation in local supply chains, where a partnership between producers and transporters prevails, ensuring inputs and services. The price of the mango pulp can of 210 Cuban pesos is high in comparison with the 300 pesos of national population average wage. The chain begins with the fruit sale price of 2,180 Cuban Pesos per tons in the primary sector and ends on the market with 40,000 Cuban pesos per ton of pulp. Figure 1 shows the map of supply chain at local level. Each actors work as an independent company, connected by material, financial and information flow. The inter-business cooperation is developed in the framework of commodity-money relations between actors, and lack of other types of collaboration. 


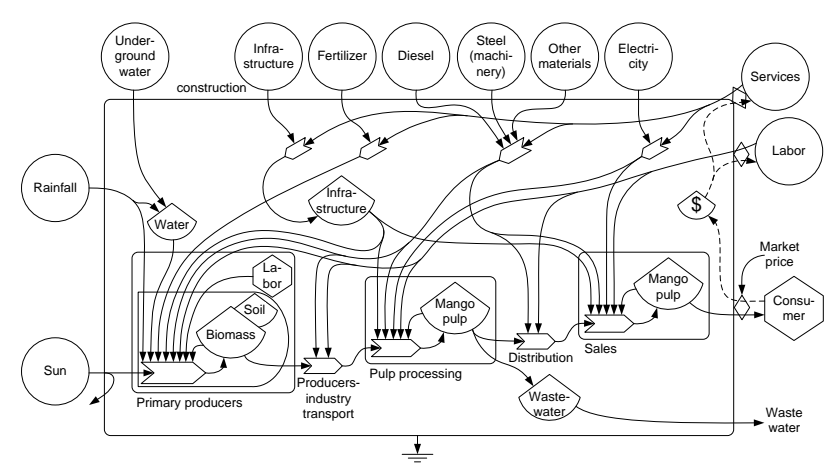

Fig. 1. Energy system diagram of the mango supply chain.

\subsection{Performance Reference Model}

The bases of reference model proposed for the assessment of supply chain at local level was adapted from the Model of Value Networks. The proposed model took into account the local conditions with small family farms that do not have a focal firm or a specialized logistics system. With this model is possible to assess each actors of the chain independently and inter-related, identifying those key points where could be improve competitiveness $[9,14]$.

The modules were selected from meetings, applying a participatory methodology, with direct and indirect actors of supply chain where were identified: infrastructure, technology, logistics, economics, environmental management and support programs and not only focusing on the logistics issues. The criteria for defining aspect was the relationship of technical and economic performance variables most relevant and which were common for companies into the chain [9]. The tool is a flexible questionnaire, which could be applied in all actors of the supply chain. Table 1 .

Table 1. Reference model for performance evaluation

\begin{tabular}{llll}
\hline \multicolumn{1}{c}{ Modulo } & \multicolumn{1}{c}{ Indicators } & \multicolumn{2}{l}{ Descriptor } \\
\hline 1.Infrastructure & Location & 1.1 & It is located in a place where there is a pro- \\
& & 1.2 & ductive organization. \\
& \multirow{3}{*}{ Installation } & 1.3 & Water and electricity supply facilities \\
& & 1.4 & Site requirements. \\
& & 1.5 & Sanitary conditions \\
& & 1.6 & Lighting conditions \\
& & 1.7 & Licenses \\
\hline 2.Human Capital & Gender & 2.1 & Female, Male \\
& Educational & 2.2 & Elemental, medium, university \\
& level & &
\end{tabular}




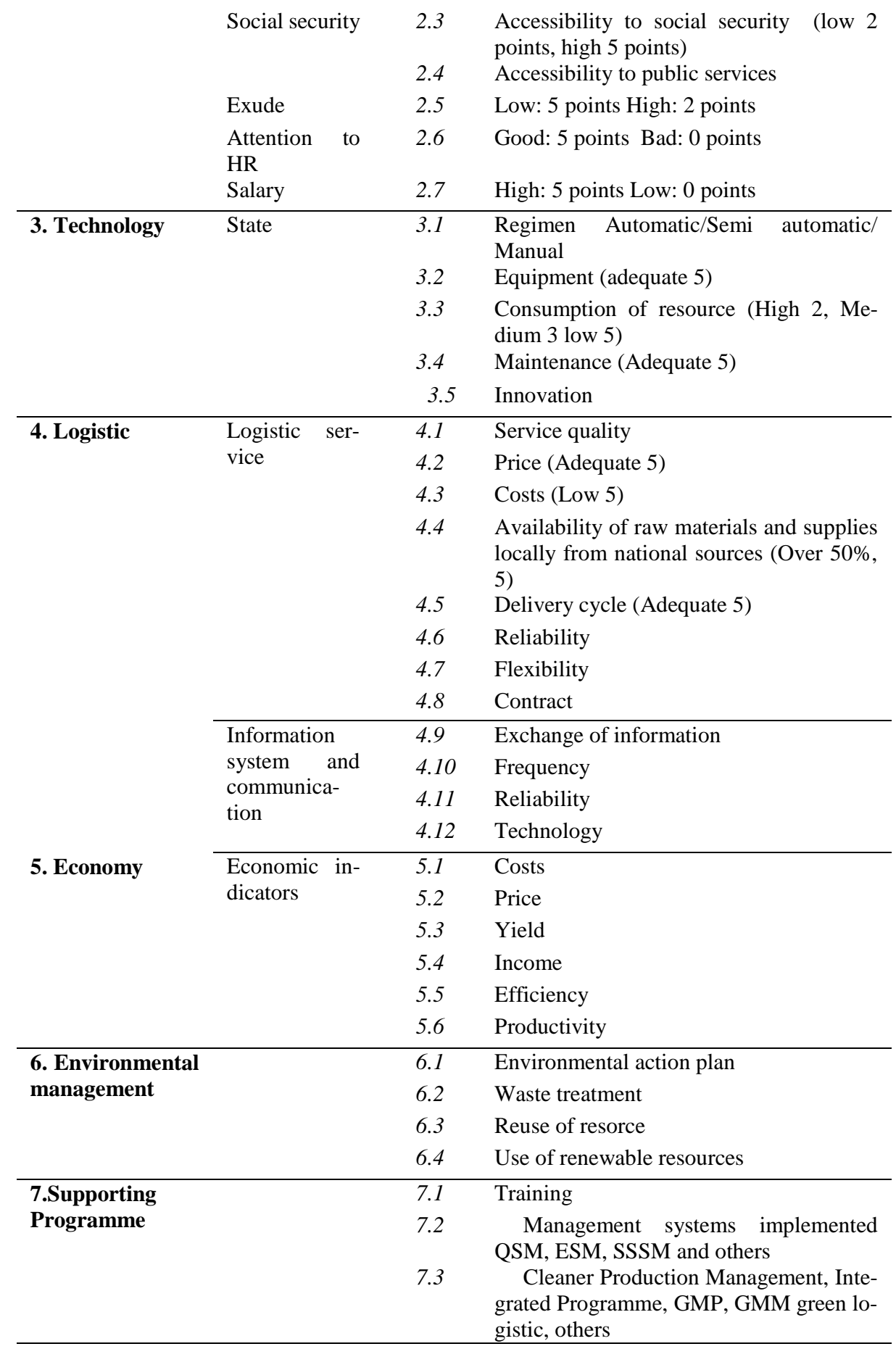




\begin{tabular}{lll}
\hline 7.4 & $\begin{array}{c}\text { Linking with national and international } \\
\text { projects }\end{array}$ \\
7.5 & Credit support programs \\
7.6 & Certifications \\
\hline
\end{tabular}

\subsection{Data Processing}

The questionnaire was applied for each direct actors but the quantity of interviewed was statistically representative at the 95,0\% confidence level. The Likert scale was used to numerically evaluate the responses of excellent $=5$; $\operatorname{good}=4$, regular $=3$, $\mathrm{bad}=2$ or very bad $=1$ [15]. It was calculated the average for each indicators and respective module. The quantitative evaluation of each actor's performance is the average of all modules. The results was showed at matrix to visualize the behavior of each direct actors of the supply chain and also gives a rating of the behavior of each indicator involved in the performance of the supply chain as a whole system. The average of performance of the actors and the average of the modules of the supply chain have the same result and it represent the qualification of the chain as a system.

The weakness of actors were considered the aspects evaluated with 1 and up 3 points, and strengths of system with 4 and 5 points $[10,15]$. The results with values between 3 and 5 was considered as the fulfillment of the basic indicators.

\section{$3 \quad$ Result and Discussion}

\subsection{Analysis of Direct Actors of Supply Chain}

Table 2 shows the results obtained by tabulating the questionnaires from actors of supply chain. The matrix allows viewing that the supply chain has problem with technology (2.8), logistics aspects (2.8), environmental management (2.5) and supporting program (1.9) for a general qualification of 2.9 points. These results indicate the need for an internal strategy for performance improvement of each direct actors, and public policy to establish a local development program.

Table 2. Evaluation matrix of supply chain at the local level

\begin{tabular}{lcccccc}
\hline Module & $\begin{array}{c}\text { Primary } \\
\text { producer }\end{array}$ & $\begin{array}{c}\text { Fruit trans- } \\
\text { port }\end{array}$ & $\begin{array}{c}\text { Pulp pro- } \\
\text { cessing }\end{array}$ & $\begin{array}{c}\text { Pulp } \\
\text { trans- } \\
\text { port }\end{array}$ & Market & $\begin{array}{c}\text { Supply } \\
\text { chain }\end{array}$ \\
\hline Infrastructure & 3,6 & 2,2 & 3,6 & 2,2 & 4,0 & 3,4 \\
Human capital & 4,1 & 3,0 & 4,4 & 3,0 & 4,1 & 3,9 \\
Technology & 2,5 & 2,8 & 2,3 & 2,8 & 3,8 & 2,9 \\
Economy & 3,2 & 3,0 & 3,0 & 3,0 & 3,2 & 3,1 \\
Logistic & 2,0 & 2,8 & 3,4 & 2,8 & 3,0 & 2,7 \\
Environmental & & 2,0 & 3,2 & 2,0 & 2,0 & 2,4 \\
management & 2,3 & 2,0 & & & & \\
\hline
\end{tabular}




\begin{tabular}{lllllll}
\hline Supporting pro- & & & & & & \\
gram & 2,3 & 2,0 & 2,3 & 2,0 & 1,0 & 1,9 \\
Average & 2,9 & 2,4 & 3,4 & 2,4 & 3,0 & $\mathbf{2 , 9}$ \\
\hline
\end{tabular}

Primary Producers. The results show that the primary producer needs deep internal improvements to increase performance in technology (2.5), logistics (2.0) and support program (2.5). Figure 2. The level of mechanization for pruning, fertilizing and harvesting is low due to using obsolete equipment and there is not local company that provides spare parts or perform equipment maintenance. The aspect of innovation was assessed as bad because it have not technology to add value to production as selection and washing fruit. The economic indicators was evaluated as regular due to low yield of $10 \mathrm{t} / \mathrm{ha}$ compared with similar system of $20 \mathrm{t} / \mathrm{ha}$, and high cost which shows that the current model of agricultural economy is characterized by little use of natural resources, the use of chemical fertilizers and great presence of labor. The assessment for this actor show that $41.3 \%$ of the aspect were evaluated as reasonable, $32.6 \%$ as bad, $10.9 \%$ as good, $8,7 \%$ as excellent and $6.5 \%$ as very bad which compliance of $57.4 \%$ of the basic indicators. The general assessment was 3 points. The most critical modules were technology, environment management, supporting programs and logistics system affected by the delivery planning, centralization, instability, low availability of inputs and unappropriated information communication, as well as high prices of service delivery and problems with hiring companies.

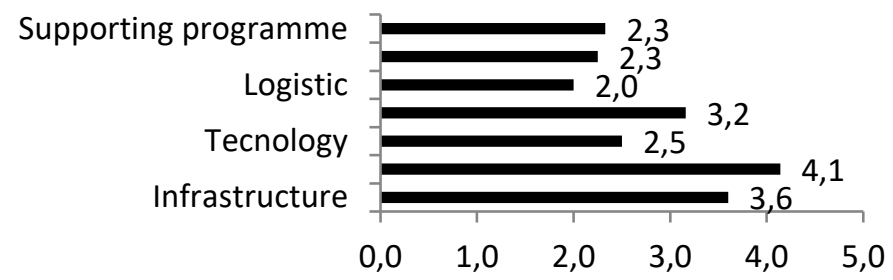

Fig. 2. Results of performance evaluation of Primary Producers

Pulp Processing. The pulp-processing actor needs to improve the production technology (2.3 points) and support programs (2.0 points). Figure 3 . The obsolete technology, lack of automation in the process, high energy and water consumption influences in the number of hired workers. It is reflected in economic indicators such as production costs, efficiency and low yield. The infrastructure conditions were evaluated with 3.6 points due to the situation of roads, lack of space and lighting. The support programs was evaluated with 2.5 points and only the aspect of training received regular evaluation. The precariousness of technology and infrastructure, as well as difficulty in acquiring credits and financing limits the ability of management systems certification, which depend on these resources. The overall evaluation was 3.2 point with $64.4 \%$ of compliance of the basic indicators. $45.7 \%$ of the aspects were assessed as regular, $19.6 \%$ as 
bad, $21.8 \%$ as good, $10.9 \%$ as excellent and $2.2 \%$ as very bad. The supporting programs and the technology were the most critical modules.

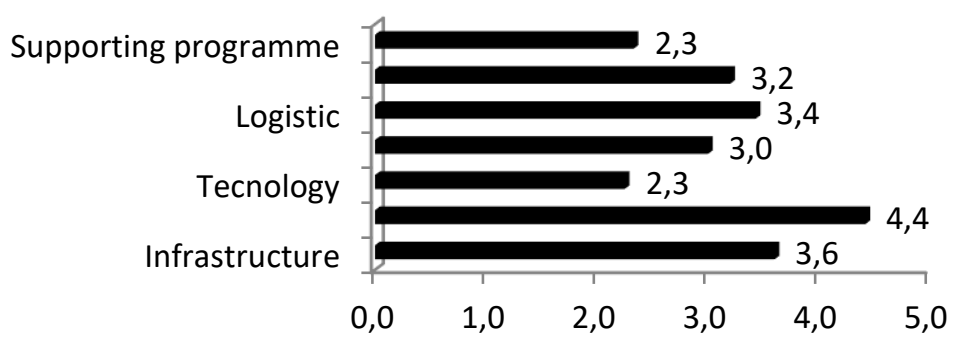

Fig. 3. Results of performance evaluation of pulp processing

Distributors and Transporters. The infrastructure module was evaluates inappropriate for both the road conditions (mountain) makes it difficult to access collection points of fruits and pulps and trucks are not suitable increasing the risk of production loss and quality of fruit. Compared with the previous links, the human resources module was evaluated with 3.0 points because employees are not paid for production; it has a fixed salary, and working conditions that are not appropriate. This factor causes instability, increases the exodus of workers, and affects the logistical costs of the rest of the actors. According to Bourlakis [3] and Grimm et al. [4], the link between small producers and consumers are complex chains of collection and distribution which producers have been traditionally submitted, and contributed to the decline profitability. The rating for each module was as follows: $41.3 \%$ of the descriptors were assessed as regular, $47.8 \%$ as bad, $2.17 \%$ was evaluated as good, $6.5 \%$ as excellent and $2.2 \%$ as very bad for an overall assessment of 2.8 point. The most critical modules were the technology, infrastructure, logistics, environment and supporting programs. Indicating a compliance of $56.8 \%$ of the basic indicators. Figure 4 shows the evaluation of this actor.

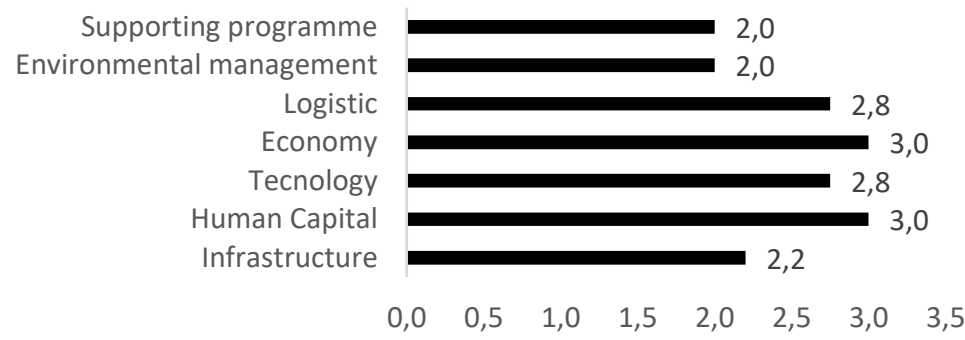

Fig. 4. Results of performance evaluation of distributing and transporting actors 
Market. This actor bases its operation on mobile outlets appropriated to the local environment because do not require refrigeration to preserve the pulp of mango. One factor that affects product sales is an informal market that can set prices for products according to the quality levels, the season and demand. The critical aspects for this actor are the information and communication system. This actor evaluated as very bad the module of supporting programs because it is not offered programs or funding to develop marketing.

The $32.6 \%$ of the descriptors were assessed as regular, $10.86 \%$ as bad, $23.9 \%$ as good, $1521 \%$ as excellent and $17.4 \%$ as very bad. Most critical modules were the supporting programs and systems of information and communication. The overall assessment was of 3 point indicating a compliance of $60 \%$ of basic indicators. Figure 5 shows results of performance evaluation of sales actors.

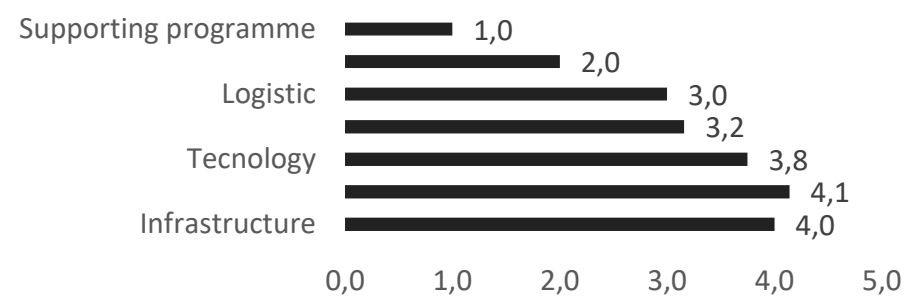

Fig. 5. Results of performance evaluation of sales actors

\subsection{Analysis the Supply Chain as a Whole System}

One of the strengths of this supply chain is the infrastructure and humans resource because is located in an area where there is a production base, with experience in mango cultivation, with favorable climatic conditions and organizational structures such as cooperatives to help manage the primary producer. The inclusion of women to labor, free access to medical and educational services and laws that guarantee the social security of members of the chains it was also appointed however, the exodus is indicating that the concrete measures to ensure the stability of labor actions could be done.

The technology module is a weakness in all actors and the whole supply chain. All actors have problem to introduce innovation in the production process where only processing actor adds value but still quite limited. It confirms that supply chains at local level lose opportunities to participate effectively in global value chains or other premises due to not being properly equipped.

The other module that is evaluated as ruin was the logistic. De Oliveira et al. [9] identified in studies a low degree of implementation in small and medium enterprises (SMEs) which have not investment capacity and an organizational structure to facilitate the implementation of TIC, however, it can provide potential benefits such as reduced cycle times, reduced inventories, minimize the whip effect, and improve the effectiveness of distribution channels. 
In the national context in addition to the elements of macroeconomic policy there are other factors such as institutional aspects, given the fragility of both public and private organizations and sectorial vision limiting and difficult coordination. Producers tend to organize themselves into cooperatives but they could not capitalize to invest in processing. It have not appropriated mechanism for institutional support allowing access to financing channels. The main obstacles to access to credit by the direct chain actors is the disinterest from financial agents due to small value transactions, required guarantees and necessary documentation cost.

The other problem is the absence of environmental action plan and supporting programe in all actors. Van Hoof et al. [6] showed that companies arising from small economies scale with improved environmental performance and cost reduction are those with higher levels of collaboration capabilities and involves the assimilation and transfer of knowledge and changes organizational. In the other hand, according to Bourlakis [3] practices and implementation of development programs and audits are slow and expensive for these companies. However, better management will improve the economic, environmental and social performance of local supply chains supported by Quality Management System, Hazard Analysis and Critical Control Point Systems, Health and safety, environmental management systems, among others.

However, this scenario could be different if some cleaner production practices were implemented. To improve the performance of primary producers, $25 \%$ of chemical fertilizers were replaced by compost made from agricultural waste and solid waste from the small industry; new ones built from pruning residues replaced fruit containers; improvements in harvest organization allowed $50 \%$ reduction in labor force and $25 \%$ in fuels consumption. The use of animal traction when the efficient use of vehicles is limited and the poor state of the roads is also a viable option besides keeping animals on the property. The replacement of $50 \%$ of transportation by animal traction was considered to both producers-industry and distribution transportation. This action allows reducing in the same proportion the transportation machinery, labor and fuel consumption. New routes were organized prioritizing the most distant selling points and allowing direct purchase by the mobile sellers at the processing industry.

The application of good management practices, such as reorganization of production and technological flows, allowed to rise up the $75 \%$ processing installed capacity and to reduce the processing period from 5 to 3 months without any investment. An extra payment to primary producers supplying fruit directly to industry increased the production yield from 2.3 to $1.9 \mathrm{t}$ of fruit / $\mathrm{t}$ of pulp. Additionally, the use of rain water for pulp cans cooling, its reuse in cleaning activities, the recirculation of water in the fruit washing machine were performed to reduce water consumption. The cleaner production and management training programs allowed increasing knowledge and motivation in finding sustainable solutions. The measures allowed savings of $50 \%$ water, $25 \%$ electricity and $40 \%$ wood. The labor force was reduced by $25 \%$ but was relocated to support services to the mango crop. Two points of sale were built with more simple structures, suitable for rural areas, because the mango pulp could be preserved without refrigeration. 


\section{Conclusion}

The model to evaluate the sustainable performance of supply chain allowed to measure scope of the supply chain. The identification and better understanding of the obstacles that limit the development of the supply chain have a great importance for both the refinement of public policies and for awareness and decision-making of companies operating in the sector. In this case, the supply chain studied should be designed to increase the autonomy of producers; restructure the existing system; modify the storage and distribution system, incentives for technological innovation and added value, adopt new and sound environmental technologies; proper management of resources; reducing input costs, and reducing the intermediation between actors. This study also confirm the critical factors identified by $[2,4,16,17]$ among others authors about performance of supply chain at local level. However, other studies should be made and analysis other supply chains to validate the proposed model for performance evaluation of supply chain at local level. The advantage to use this model is it allowed the comparison between the actors, identify their strengths and weaknesses as well as enables them to connect in an integrated system in order to accompany the indicators and changes in strategy at local level into a single matrix for decision-making from vision and perception of the actors.

Note that three pillars of sustainability also were addressed in the analysis and it was considering social aspects absent in the most article as multiculturalism, gender, ability, exodus, access to services public and social security as well as institutional and organizational environment to support these local economies,

Acknowledgment. We would like to thank the financial support from Foundation of the State of Sao Paulo (Fundação de Amparo á Pesquisa do Estado de São Paolo. FAPESP), process no 2012/25492-0 and Pos graduation Programme of University Paulista (UNIP), Brazil. We also thank the all actors of local supply chain at local level for supplying the production data and the Laboratory of Logistics and Production Management (LOGESPRO) by support in this investigation.

\section{References}

1. Van der Heyden D, Camacho P., http://www.ruralter.org/index.php?option=com_content\&task=view\&id=38\&I

2. Briz, J. y I. De Felipe : La Cadena de Valor Agroalimentaria. Análisis Internacional de Casos Reales. Editorial Agrícola Española, S.A, Madrid, España (2011)

3. Bourlakis, M.: Firm Size and Sustainable Performance in Food Supply Chains: Insights from Greek SMEs. International Journal of Production Economics (2014)

4. Grimm J.H., Joerg S. H., Joseph, S.: Critical Factors for Sub-Supplier Management: A Sustainable Food Supply Chains Perspective, Int. J. Production Economics, (2013)

5. Correa, A., Gómez, R.A: Tecnologías de la Información en la Cadena de Suministro (2008)

6. van Hoof B, Thiell M: Collaboration Capacity for Sustainable Supply Chain Management: Small and Medium-Sized Enterprises in Mexico. Journal of Cleaner Production (2014)

7. Seuring, S., Gold, S.: Conducting Content-Analysis Based Literature Reviews in Supply Chain Management. Supply Chain Management: An International Journal, 17(5), 544-555 (2012)

8. Lambert D., Pohlen T.: Supply Chain Metrics. The International Journal of Logistics Management, 12(1), 1-19 (2001) 
9. De Oliveira J, Alexander Leite. Modelo Analítico De Suporte a Configuração e Integração da Cadeia de Suprimentos. Gest. Prod., São Carlos, 17(3), 447-463 (2010)

10. Acevedo, J. Gómez M, López T, Acevedo AJ, Pardillo Y: "Reference Model Value Networks for Sustainable Development". Revista de Investigación Agraria y Ambiental, UNAD, Colombia, 2, 29-50 (2010)

11. Sellitto M A; Mendes L.W.: Avaliação Comparativa do Desempenho de Três Cadeias de Suprimentos em Manufatura. Produção, 16(3), 552-568 (2006)

12. Gomes, C.; Yasim, M.; Lisboa, J. An Examination of Manufacturing Organizations's Performance Evaluation: Analysis, Implications and a Framework for Future Research. International Journal of Operations and Production Management, 24(5), 488-513 (2012)

13. Seuring, S.: A Review of Modeling Approaches for Sustainable Supply Chain Management. Decision Support Systems (2013)

14. Chan, F.; QI, H.: Feasibility of Performance Measurement System for Supply Chain: A Process-Based Approach and Measures. Integrated Manufacturing Systems, 14(3), 179-190 (2003)

15. Torres L.: Diseño de un Modelo de Referencia para la Evaluación de Microindustrias. La Habana (2012)

16. Min, H., \& Kim, I.: Green Supply Chain Research: Past, Present, and Future. Logistics Research, 4, 39-47 (2012)

17. López T Acevedo J, Gómez M: Cadena de Suministro Agroalimentaria Municipio Marianao Nueva Empresa. Revista Cubana de Gestion Empresarial, 7(3), 20-30 (2012) 